\title{
Payment Evasion
}

Stefan Buehler, Daniel Halbheer, Michael Lechner

November 2014 Discussion Paper no. 2014-35 


$\begin{array}{ll}\text { Editor: } & \text { Martina Flockerzi } \\ & \text { University of St.Gallen } \\ & \text { School of Economics and Political Science } \\ & \text { Department of Economics } \\ & \text { Bodanstrasse 8 } \\ & \text { CH-9000 St. Gallen } \\ & \text { Phone } \quad+41712242325 \\ & \text { Fax } \quad+41712243135 \\ & \text { Email seps@unisg.ch } \\ & \text { School of Economics and Political Science } \\ & \text { Department of Economics } \\ & \text { University of St.Gallen } \\ & \text { Bodanstrasse } 8 \\ \text { Publisher: } & \text { CH-9000 St. Gallen } \\ & \text { Phone +41 71 224 23 25 } \\ & \text { Fax }+41712243135 \\ & \text { http://www.seps.unisg.ch }\end{array}$




\title{
Payment Evasion $^{1}$
}

Stefan Buehler, Daniel Halbheer, Michael Lechner

Author's address:

\author{
Prof. Stefan Buehler \\ FGN-HSG \\ Varnbüelstrasse 19 \\ $\mathrm{CH}-9000$ St. Gallen \\ Phone $\quad+41712242303$ \\ Fax $\quad+41712242874$ \\ Email stefan.buehler@unisg.ch \\ Website www.fgn.unisg.ch
}

Associate Prof. Daniel Halbheer

HEC Paris

Department of Marketing

1 , rue de la Libération

78351 Jouy-en-Josas Cedex

France

Email halbheer@hec.fr

Prof. Michael Lechner

SEW-HSG

Varnbüelstrasse 14

$\mathrm{CH}-9000$ St. Gallen

Phone $\quad+41712242814$

Fax $\quad+41712242302$

Email michael.lechner@unisg.ch

Website www.sew.unisg.ch

\footnotetext{
1 The authors thank the Zurich Transport Network ZVV, Hofwiesenstrasse 370, 8090 Zurich, and in particular Peter Nordenson, for providing the data, as well as Berno B"uchel, Aaron Edlin, Preyas Desai, Markus Reisinger, and seminar participants at the University of Hamburg, the University of Lausanne, and the University of Nuremberg for helpful comments and suggestions.
} 


\begin{abstract}
This paper models payment evasion as a source of profit by letting the firm choose the price charged to paying consumers and the fine collected from detected payment evaders. The consumers choose whether to purchase, evade payment, or refrain from consumption. We show that payment evasion allows the firm to charge a higher price to paying consumers and to generate a higher profit. We also show that higher fines do not necessarily reduce payment evasion. Finally, we provide empirical evidence which is consistent with our theoretical analysis, using comprehensive micro data on fare dodging on the Zurich Transport Network.
\end{abstract}

\title{
Keywords
}

Payment Evasion, Pricing, Fine, Self-Selection. 


\section{Introduction}

Payment evasion — fraudulent consumption by nonpaying consumers — is a serious issue for firms in different industries. There are various ways in which consumers might obtain a product or service without payment, including shoplifting (Yaniv 2009, Perlman and Ozinci 2014), wardrobing (Timoumi and Coughlan 2014), and digital piracy (Chellappa and Shivendu 2005, Vernik et al. 2011). ${ }^{1}$ Another classic example for payment evasion is fare dodging on public transportation (Boyd et al. 1989, Kooreman 1993). ${ }^{2}$

Standard price theory abstracts from payment evasion and posits the excludability of nonpaying consumers based on pricing alone. Or, as Hirshleifer et al. (2005, p. 19) put it: "To acquire a commodity buyers must be willing to pay the market price [...]." The implicit assumption is, of course, that the consumers' cost associated with payment evasion are high enough for them to refrain from fraudulent consumption. It is well known, though, that many products exhibit some degree of nonexcludability (Novos and Waldman 1984). Several legal instruments have been designed to enforce the exclusion of nonpaying consumers, including patents, copyrights, and trade marks. Yet, since the enforcement by public agencies is sketchy and varies across jurisdictions, firms undertake substantial private investments in technologies to detect and punish payment evasion. Antitheft devices, video-surveillance cameras, and digital rights management systems all serve this purpose. It is fair to say that firms spend great effort on managing payment evasion, but they rarely eliminate it.

In line with this observation, this paper models payment evasion as a source of profit for the firm. Our focus is therefore on the management of payment evasion, rather than its elimination. Key to our analysis is the firm's ability to collect fines-albeit limited up to a maximum admissible level mandated by law-from consumers detected as payment evaders. ${ }^{3}$ In such a setting, there are two sources of revenue: paying consumers and payment evaders. We develop a model in which the firm chooses both the price charged to paying consumers and the fine faced by payment evaders in order to maximize its expected profit. An important feature is that the demands from paying consumers and payment evaders are interdependent. Observing the price and the fine, consumers can

\footnotetext{
${ }^{1}$ Belleflamme and Peitz $(2012,2014)$ provide a comprehensive survey and a recent update on the theory of digital piracy.

${ }^{2}$ Recent evidence from the US shows that shoplifters steal more than $\$ 13$ billion worth of goods from retailers every year (National Association for Shoplifting Prevention 2014); return fraud costed retailers more than $\$ 9$ billion in 2013 (National Retail Federation 2014); the consumption of digitally pirated music in 2008 is estimated to be between $\$ 7$ and $\$ 20$ billion (Frontier Economics 2012).

${ }^{3}$ Retailers, for instance, regularly impose in-store penalties for shoplifting. Under New York's state law, retailers may collect a penalty "not to exceed the greater of five times the retail price of the merchandise" (N.Y. GOB. LAW $\S 11-105)$.
} 
choose among three options: purchase, evade payment, or refrain from consumption. The extent of payment evasion is thus endogenously determined by the interplay of firm and consumer decisions. ${ }^{4}$

The paper consists of a theoretical part and an empirical part. In the theoretical part, we derive three key results. First, paying consumers "overpay," as the firm charges them higher prices than in the absence of payment evaders. The reason is that an increase of the regular price turns some paying consumers into payment evaders who can potentially be fined, rather than driving them out of the market. In effect, payment evasion allows the firm to discriminate the prices of physically homogenous products: Regular consumers pay the regular price, whereas payment evaders face the expected fine. That is, payment evasion leads to a peculiar form of price discrimination where the regular price exceeds the expected fine (otherwise there would be no payment evasion). Second, the firm has no incentive to fully deter payment evasion, resulting in so-called "underdeterrence." This result follows from the fact that the firm can generate extra profit from payment evaders, provided that the enforcement technology is sufficiently effective. Third, higher fines do not necessarily reduce payment evasion. The reason is that an increase in the fine has two countervailing effects on payment evasion: a direct negative effect and an indirect positive effect via the induced increase of the regular price (which turns some regular consumers into payment evaders). For an unambiguously negative effect, the price-mediated effect must be small enough.

In addition, we provide two relevant extensions of the model. First, we generalize the pricing rule to a setting where the firm can influence the detection probability through the choice of costly effort. Second, we allow the firm to invest in technological protection in order to raise the consumers' cost of evading payment.

In the empirical part, we examine payment evasion on the Zurich Transport Network (ZVV). Using data on the universe of detected payment evaders, we find the following main results. First, compared to the reference population of ZVV passengers constructed from census data, both male and young passengers are significantly overrepresented among payment evaders. Second, in line with our theoretical analysis, the ZVV does not fully deter payment evasion, although it consistently sets the maximum admissible fines. Third, analyzing the effect of an exogenous increase in the maximum admissible fines, we find no significant reduction of payment evasion, neither at the aggregate level nor for different types of payment evaders (even though prices were approximately held

\footnotetext{
${ }^{4}$ This is a natural extension of standard price theory. Alternatively, one might assume that an exogenous share of consumers are 'born' payment evaders who never pay or exit the market (irrespective of price, fine, or type). Yet, such an assumption can neither explain the extent of payment evasion nor the choice of the price and fine in the presence of payment evasion.
} 
constant). This finding is explained by the relatively small increase in the fines and the concurrent reduction in the detection probability by the ZVV.

Our paper intends to contribute to two strands of literature. First, we introduce the notion of payment evasion into the pricing literature and show that it naturally leads to a peculiar form of price discrimination. Our optimal pricing rule takes the revenues from paying consumers and payment evaders explicitly into account and extends the classic Ramsey pricing rule (Ramsey 1927) to this new setting. Importantly, payment evasion is endogenously determined by the interplay of profit maximizing decisions by the firm and rational consumer choices (Becker 1968, Ehrlich 1996). ${ }^{5}$ Second, we add to the empirical literature on the effect of enforcement on unlawful behavior (Levitt 1997, DiTella and Schargrodsky 2004, DeAngelo and Hansen 2014), combining firm-level data on private enforcement and comprehensive passenger-level data on fare dodging on the ZVV. Fare dodging data offer an ideal opportunity to study payment evasion, as they provide detailed information about a large number of consumers detected as payment evaders, which is very difficult to come by in other industries. Importantly, these data allow us to estimate the empirical counterparts of the theoretical model and provide insights into the workings of private (rather than public) law enforcement (cf. Polinsky and Shavell 2000).

We organize the remainder of the paper as follows. Section 2 introduces the model and describes how consumers self-select into paying consumers and payment evaders. Section 3 studies the optimal choice of the price and fine and analyzes the profit impact of payment evasion. Section 4 illustrates these results by means of an example. Section 5 provides empirical evidence using passenger-level data on payment evasion from the ZVV. Conclusions and directions for future research are offered in Section 6.

\section{The Model}

We first introduce the decision makers in our model: the firm and the consumers. Next, we derive the demand of paying consumers and the demand for payment evasion and study how the demand functions depend on the price and the fine, as well as the cost of evading payment.

\subsection{Firm}

We consider a firm that offers a product (or service) to consumers who have the possibility to buy it or obtain it without payment. The fixed cost of providing the product is $F>0$

\footnotetext{
${ }^{5}$ Rational consumer choices also give rise to payment evasion under pay-as-you-wish pricing (Chen et al. 2013). The key difference is that, under such a pricing scheme, payment evasion is tolerated and not subject to a fine.
} 
and $c \geq 0$ denotes the constant unit cost. The firm chooses the price $p$ at which it sells its product and the monetary fine $f$ that is levied on payment evaders when they are being detected. We let $\left(\pi, F_{\pi}\right)$ denote the detection technology that allows the firm to detect payment evasion with probability $\pi \in[0,1]$ after investing $F_{\pi}>0$. For $\pi<1$, detection is uncertain and assumed equally likely for all consumers (Polinsky and Shavell 2000). We initially assume that the firm's detection technology is exogenously given and relax this assumption later on by letting the technology be endogenously determined by the firm's costly effort.

Following Becker (1968), we assume that the size of the monetary fine is constrained by legal requirements. ${ }^{6}$ Formally, this means that the fine set by the firm cannot exceed the maximum admissible fine $\bar{f}$, where $0 \leq \bar{f}<+\infty$. In addition, we assume $\pi \bar{f} \geq c$, meaning that the detection technology is "sufficiently effective." If no such technology were available, the firm could not recoup the unit cost with the highest possible expected fine, which in turn implies that payment evasion cannot be an additional source of profit.

\subsection{Consumers}

We consider a market with a mass of $N$ potential consumers who observe the price $p$ and the fine $f$ before making a choice. Consumers have unit demand and can choose among three options: (i) purchase the product, (ii) obtain the product without payment, or (iii) choose the outside option to not obtain the product. When purchasing, a consumer obtains the product at price $p$. In contrast, when evading payment, a consumer obtains the product incurring the evasion cost $k \geq 0$ and facing the risk of being fined with the amount $f$. The evasion cost may reflect the difficulty to obtain the product without payment or the moral cost of evading payment (Chellappa and Shivendu 2005). We assume that the consumers have identical beliefs $\phi \in[0,1]$ about the detection probability $\pi$ and thus expect to be fined with the amount $\phi f$ when evading payment. When consumers have rational expectations, the belief $\phi$ coincides with the actual detection probability $\pi$.

Preferences. Suppose that consumers have an indirect utility function which allows them to rank the options in a consistent and unambiguous manner. Their heterogeneity in taste is captured by the type $\theta$, which represents a consumer's marginal willingness to pay for quality (Mussa and Rosen 1978). The types are drawn independently from a distribution with density function $g(\theta)$ and cumulative distribution function $G(\theta)$ on

\footnotetext{
${ }^{6}$ The highest conceivable monetary fine is the wealth of a payment evader, which the firm usually cannot appropriate.
} 
$[0,+\infty)$, where $g(\theta)>0$ for all $\theta, G(0)=0$, and $G(+\infty)=1$. Specifically, a consumer with type $\theta$ has the following indirect utility function:

$$
V(p, f ; \theta, \phi, k)=\max \left\{\max \left\{v_{P}(p ; \theta), v_{E}(f ; \theta, \phi, k)\right\}, 0\right\},
$$

where $v_{P}(p ; \theta)$ and $v_{E}(f ; \theta, \phi, k)$ denote the conditional indirect utilities of obtaining the product with payment and evading payment, respectively. The conditional indirect utility function depends on the relevant price and the consumer's type; in addition, the notation $v_{E}(f ; \theta, \phi, k)$ captures that the utility of a payment evader also depends on the belief about the detection probability and the cost of evading payment. For convenience, we normalize the utility of the outside option to zero. Throughout the paper, we impose the following assumption:

Assumption 1 (Indirect Utility). (i) The function $v_{E}(f ; \theta, \phi, k)$ is increasing in $\theta$ and there is $\underline{\theta} \in[0, \infty)$ such that $v_{E}(f ; \underline{\theta}, \phi, k)=0$. (ii) The difference $v_{P}(p ; \theta)-v_{E}(f ; \theta, \phi, k)$ is increasing in $\theta$ and there exists $\bar{\theta} \in[\underline{\theta}, \infty)$ satisfying $v_{P}(p ; \bar{\theta})=v_{E}(f ; \bar{\theta}, \phi, k)>0$.

Assumption 1 assures that consumers self-select into one of three segments. The type $\bar{\theta}(p, f ; \phi, k)$ denotes the consumer who is indifferent between purchasing and evading payment; thus consumers with type $\theta \geq \bar{\theta}(p, f ; \phi, k)$ purchase the product. Instead, the consumer who is indifferent between evading payment and choosing the outside option has type $\underline{\theta}(f ; \phi, k)$; thus consumers with type $\theta \leq \underline{\theta}(f ; \phi, k)$ refrain from consumption. Consequently, the remaining consumers with a type $\theta$ below $\bar{\theta}(p, f ; \phi, k)$ but above $\underline{\theta}(f ; \phi, k)$ obtain the product evading payment. Notice that Assumption 1 implies that the consumers who evade payment suffer from a perceived quality degradation (Yaniv 2009, Belleflamme and Peitz 2012). ${ }^{7}$ Figure 1 illustrates the consumers' decisions as a function of their type.

Demand Segments. The size of the respective demand segments is determined by the cut-off values, accounting for the distribution of consumer types in the population. Therefore, the demand of paying consumers is given by

$$
\begin{aligned}
D(p, f ; \phi, k) & =N \int_{\bar{\theta}(p, f ; \phi, k)}^{+\infty} g(\boldsymbol{\theta}) d \boldsymbol{\theta} \\
& =N[1-G(\overline{\boldsymbol{\theta}}(p, f ; \phi, k))] .
\end{aligned}
$$

\footnotetext{
${ }^{7}$ Put differently, the consumption utility is lower if the product is obtained without payment. In the case of fare dodging, for instance, a paid train ride might be perceived as more comfortable than the same train ride without payment.
} 


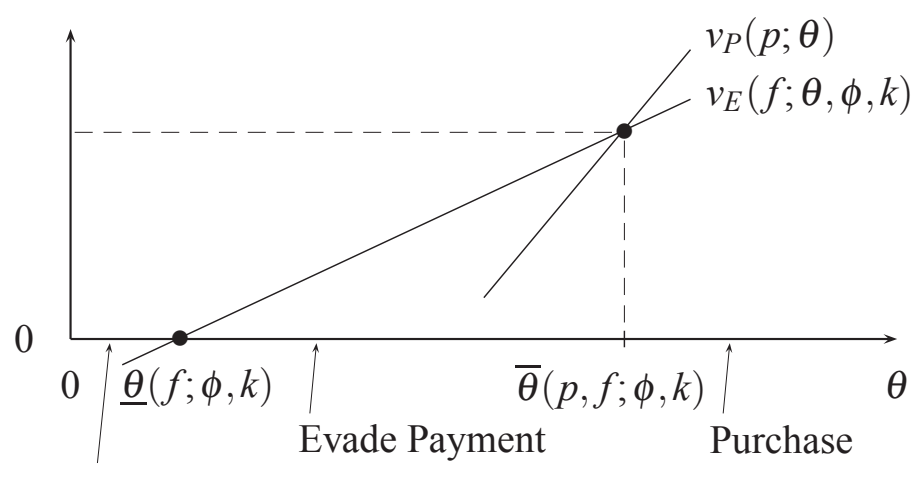

Leave the market

Figure 1: Cut-Off Values and Consumer Decisions.

We impose the following assumption on this demand: ${ }^{8}$

Assumption 2 (Demand). The demand of paying consumers $D(p, f ; \phi, k)$ satisfies the following properties: $\frac{\partial}{\partial p} D<0, \frac{\partial}{\partial f} D>0, \frac{\partial}{\partial k} D>0, \frac{\partial^{2}}{\partial p^{2}} D \leq 0, \frac{\partial^{2}}{\partial f \partial p} D \geq 0$, and $\frac{\partial^{2}}{\partial k \partial p} D \geq 0$ for all $(p, f)$.

The demand of paying consumers depends on the price $p$ and the fine $f$ and reflects the consumers' choice between purchasing and evading payment. Assumption 2 means that the demand is decreasing in price and increasing in both the fine and the cost of evading payment $k$; the higher order derivatives mean that demand is concave in price and more sensitive to changes in price when the fine or the evasion costs are higher.

Assumption 1 implies that $\underline{\theta}(f ; \phi, k) \leq \bar{\theta}(p, f ; \phi, k)$. Thus, the demand for the outside option is given by

$$
\begin{aligned}
X(f ; \phi, k) & =N \int_{0}^{\underline{\theta}(f ; \phi, k)} g(\theta) d \theta \\
& =N[G(\underline{\theta}(f ; \phi, k))] .
\end{aligned}
$$

We impose the following assumption on this demand:

Assumption 3 (Outside Option). The demand for the outside option $X(f ; \phi, k)$ satisfies $\frac{\partial}{\partial f} X>0$ and $\frac{\partial}{\partial k} X>0$ for all $f$.

\footnotetext{
${ }^{8}$ We follow the standard approach and impose the assumption directly on the demand function $D(\cdot)$. An alternative approach would be to state this assumption in terms of the underlying indirect utility functions $v_{P}(\cdot)$ and $v_{E}(\cdot)$. Appendix A establishes the relationship between the two approaches.
} 
Assumption 3 states that a higher fine or higher evasion costs are associated with an increase of the demand for the outside option. Notice that the demand for the outside option depends on the fine but not the price, as it reflects the consumers' choice between evading payment and refraining from consumption.

By construction, the consumers with a taste parameter below $\bar{\theta}(p, f ; \phi, k)$ but above $\underline{\theta}(f ; \phi, k)$ obtain the product evading payment. This gives rise to the following definition of payment evasion:

Definition 1 (Payment Evasion). The demand of nonpaying consumers is given by $E(p, f ; \phi, k)=N-D(p, f ; \phi, k)-X(f ; \phi, k)$.

This definition implies that a higher price increases payment evasion $(\partial E / \partial p>0)$, mirroring the associated reduction in demand $(\partial D / \partial p<0)$. In contrast, a higher fine reduces payment evasion $(\partial E / \partial f<0)$ due to a twofold deterrence effect: It increases both the demand of paying consumers $(\partial D / \partial f>0)$ and the demand for the outside option $(\partial X / \partial f>0) .{ }^{9}$ Higher evasion costs clearly reduce payment evasion, as some consumers with high willingness to pay now purchase while some consumers with low willingness to pay are driven out of the market as evading the payment becomes "too costly" $(\partial E / \partial k<0)$.

Definition 1 shows that the extent of payment evasion is endogenously determined by the interplay of the choices made by the firm and the consumers. In effect, payment evasion allows the firm to sells two versions of the same product at different prices to consumers with different valuations of these versions. Clearly, the two versions of the product are substitutes, implying that the demands of paying and nonpaying consumers are interdependent. As we show next, accounting for the interdependence of the demands will be important in order to determine the optimal price and fine.

\section{Managing Payment Evasion}

This section derives the optimal price and fine in the presence of payment evasion and provides the relevant comparative statics. In addition, we consider two extensions where the firm has additional tools to deal with payment evasion. First, we allow the firm to choose the effectiveness of its enforcement technology through costly effort. Second, we allow the firm to manipulate the evasion cost by investing in technological protection. To simplify exposition, we suppress the dependence on the model parameters wherever possible. Proofs are relegated to Appendix B.

\footnotetext{
${ }^{9}$ Boyd et al. (1989) provide an example of a demand function for payment evasion and simply assume that the amount of payment evasion is positively related to price and negatively related to the fine.
} 


\subsection{Optimal Price and Fine}

In the presence of payment evasion, the firm can generate profit from two consumer segments: paying consumers and payment evaders. The profit from paying consumers is $(p-c) D(p, f)$, while the expected profit from payment evaders is $(\pi f-c) E(p, f)$. The firm chooses the price and the fine in order to maximize the expected profit: ${ }^{10}$

$$
\begin{aligned}
\max _{p, f} & \Pi(p, f)=(p-c) D(p, f)+(\pi f-c) E(p, f)-F-F_{\pi} \\
\text { s.t. } \quad & p>0 \\
& 0 \leq f \leq \bar{f} .
\end{aligned}
$$

Using Definition 1, the first-order conditions for $p$ and $f$ that characterize an interior solution can be written as:

$$
\begin{array}{r}
D(p, f)+(p-\pi f) \frac{\partial D(p, f)}{\partial p}=0 \\
(p-\pi f) \frac{\partial D(p, f)}{\partial f}+\pi(N-D(p, f)-X(f))-(\pi f-c) \frac{\partial X(f)}{\partial f}=0 .
\end{array}
$$

A marginal increase in the price $p$ has the usual impact on the revenue from paying consumers, distorted upwards by the factor $-\pi f(\partial D / \partial p)$. The distortion arises because some paying consumers are diverted to the segment of payment evaders who can be fined in expectation, which in turn dampens the revenue reduction on the inframarginal units. Likewise, a marginal increase in the fine $f$ affects the revenue from expected fines, which are distorted upwards by the factor $p(\partial D / \partial f)$ as some payment evaders are induced to pay. In addition, the first-order conditions show that a marginal increase in $p$ does not affect costs, while a marginal increase in $f$ does have a cost effect. The reason for the cost-reducing effect is that some payment evaders are deterred and leave the market.

The way in which we presented the first-order conditions assumed an interior solution. The next result states a necessary condition for its existence.

Lemma 1 (Interior Solution). There is an interior solution for $p$ and $f$ only if $\frac{\partial}{\partial f} X$ is sufficiently large, that is, if the demand for the outside option is sufficiently responsive to an increase in the fine.

In effect, the condition in Lemma 1 requires that the marginal cost from consumers who are driven out of the market (extensive margin) exceeds the marginal benefit from the change in the fine (intensive margin). Put differently, Lemma 1 requires that an increase

\footnotetext{
${ }^{10}$ Throughout the analysis, we assume that the total fixed cost does not exceed the product market profit. Hence they do not change the analysis and can therefore be omitted.
} 
of the fine drives a large number of consumers into the outside option. In the example and the empirical application we provide below, it turns out that the fine is invariably set at the maximum admissible level. Consequently, we now focus on the case of a corner solution where the optimal fine $f^{*}$ is determined by the maximum admissible fine $\bar{f} .{ }^{11}$ The next result characterizes the optimal price at the constrained optimum.

Proposition 1 (Pricing). At the constrained optimum, the optimal price $p^{*}(\bar{f}, k)$ satisfies

$$
\frac{p^{*}-c}{p^{*}}=\frac{1}{\varepsilon_{p}}+\frac{\pi \bar{f}-c}{p^{*}},
$$

where $\varepsilon_{p} \equiv-(\partial D / \partial p)(p / D)$ denotes the price elasticity of demand.

Proposition 1 shows that the Lerner index-the relative profit margin-exceeds the inverse price elasticity of demand, such that regular consumers "overpay" due to the presence of payment evaders. ${ }^{12}$ This result is a consequence of the fact that an increase in the price diverts some paying consumers to the segment of payment evaders who can be fined in expectation. Put differently, the possibility to generate revenue from diverted consumers creates an incentive for the firm to raise the price above the level that would be optimal otherwise. Proposition 1 also shows that the presence of payment evaders leads to a peculiar form of price discrimination. Regular consumers pay a higher price than payment evaders pay in expectation $\left(p^{*}>\pi \bar{f}\right.$ ), even though the products are physically homogenous. The reason is that the product's perceived quality is lower if it is consumed without payment.

The maximum admissible fine and the evasion cost clearly affect the firm's choice of the optimal price. The next result illustrates the interdependencies.

Proposition 2 (Price). The optimal price $p^{*}(\bar{f}, k)$ increases in the maximum admissible fine $\bar{f}$ and the evasion cost $k$.

Proposition 2 shows that if the firm is constrained by the legal framework in setting the optimal fine, relaxing this constraint results in a higher price (and obviously a higher expected fine). The intuition is similar to that underlying Proposition 1: Because the expected fine for payment evasion goes up, it is optimal for the firm to raise the price of the regular product as well. In addition, Proposition 2 shows that higher evasion costs go along with a higher price. Intuitively, higher evasion costs create a captive segment

\footnotetext{
${ }^{11}$ The case of an interior solution can be analyzed using the first-order conditions of the unconstrained optimization problem. Comparative statics properties of the solution can then be readily determined using standard techniques.

${ }^{12}$ This result is reminiscent of multiproduct monopoly pricing with interdependent demands when the products are substitutes (Tirole 1988, p. 69).
} 
of paying consumers, allowing the firm to charge these consumers more. The next result shows how a change in the maximum admissible fine and the evasion cost affect payment evasion.

Proposition 3 (Payment Evasion). The amount of payment evasion $E^{*}(\bar{f}, k)$ decreases in the maximum fine $\bar{f}$ and the evasion cost $k$ if and only if the resulting price increase is not "too large."

Proposition 3 shows that a higher fine or higher evasion cost do not necessarily reduce the payment evasion faced by the firm. To intuitively understand this result, observe that $E^{*}(\bar{f}, k) \equiv E\left(p^{*}(\bar{f}, k), \bar{f} ; k\right)$. Even though a higher $\bar{f}$ or a higher $k$ have a dampening effect on payment evasion, the overall impact on payment evasion is generally ambiguous due to the upward pressure on the optimal price (Proposition 2). However, if the resulting price increase is not too large, the direct effect dominates the price-mediated effect, and the higher fine and the higher cost have the expected effect on payment evasion.

Finally, we analyze the profit impact of a change in the maximum admissible fine and the evasion cost. We derive the following result:

Proposition 4 (Profit). The optimized profit $\Pi^{*}(\bar{f}, k)$ increases in the maximum fine $\bar{f}$ and increases in the evasion cost $k$ if and only if the ratio of consumers who are driven out of the market to diverted consumers is not "too large."

This result shows that the firm's ability to levy heavier fines on payment evaders increases the firm's profit-even when it results in higher payment evasion and lower demand. Intuitively, Proposition 4 holds because a higher $\bar{f}$ allows the firm to generate higher markups on both paying consumers and payment evaders, which compensate for the reduction in profit due to the diversion of demand. Proposition 4 also shows that an increase in the evasion cost affects firm profitability: Even though the firm can generate a higher markup on paying consumers, the reallocation of consumers across demand segments can reduce the overall profit. Obviously, the profit is reduced if the increase in the evasion cost induces many consumers to choose the outside option.

\subsection{Endogenous Detection Probability}

To endogenize the choice of the detection technology, we now assume that the firm can influence both the detection probability and the cost of the detection technology through its choice of costly effort. To this end, we extend our model to a setting where the firm makes sequential decisions. Specifically, we consider the following two-stage game: In stage 1 , the firm chooses the price $p$ and the fine $f$, subject to the constraints $p>0$ and 
$0 \leq f \leq \bar{f}$. In stage 2 , the firm chooses the control effort $e \geq \underline{e}$, where $\underline{e}$ is the lowest admissible effort that satisfies the condition $\pi(\underline{e}) \bar{f} \geq c$ and thus gives rise to a sufficiently effective detection technology. The control effort determines the detection probability $\pi(e)$ and the cost of the technology $F_{\pi}(e)$. This timeline captures a business environment in which the control effort can be varied in the short run, whereas the price and the fine are chosen in the long run. ${ }^{13}$

The firm's (short run) effort choice problem is to

$$
\max _{e \geq \underline{e}} \Pi(e ; p, f)=(p-c) D(p, f)+(\pi(e) f-c) E(p, f)-F-F_{\pi}(e),
$$

where we assume that $\pi(e)$ is strictly concave, with $\pi(0)=0$ and $\pi(+\infty)=1$, and that the effort $\operatorname{cost} F_{\pi}(e)$ is strictly convex, with $F_{\pi}(0)=0$. Solving the game using backward induction, we derive the following result.

Proposition 5 (Effort Choice). Denote by $\varepsilon_{p} \equiv-(\partial D / \partial p)(p / D)$ the price elasticity of demand and by $\varepsilon_{f} \equiv-(\partial E / \partial f)(f / E)$ the elasticity of payment evasion with respect to the fine $f$. (i) At the constrained optimum, the optimal price $p^{*}(\bar{f})$ is a solution to

$$
\frac{p^{*}-c}{p^{*}}=\frac{1}{\varepsilon_{p}}+\frac{\pi\left(e^{*}\right) \bar{f}-c}{p^{*}},
$$

and the implied optimal effort $e^{*}(\bar{f})$ solves $\pi^{\prime}\left(e^{*}\right) f E\left(p^{*}, \bar{f}\right)-F_{\pi}^{\prime}\left(e^{*}\right)=0$. (ii) The price $p^{*}(\bar{f})$ increases in $\bar{f}$, and the effort $e^{*}(\bar{f})$ decreases in $\bar{f}$ if $\varepsilon_{f}>1$ and increases in $\bar{f}$ if the inequality is reversed.

This result shows that the pricing rule and its comparative statics (Propositions 1 and 2, respectively) generalize naturally to settings where the probability of detection is endogenous. In addition, Proposition 5 shows that the comparative statics with respect to $\bar{f}$ are similar to the predictions in the law and economics literature: The costly effort decreases in response to an increase in the fine if payment evasion is sufficiently reduced by an increase in $\bar{f}$. Intuitively, the same level of deterrence can be attained with a lower effort level, which results in both a lower detection probability and lower enforcement costs.

\subsection{Endogenous Technological Protection}

We now assume that the firm can invest in technical protection to raise the evasion cost borne by consumers before it chooses the price and the fine. ${ }^{14}$ Again, we consider a

\footnotetext{
${ }^{13}$ The timeline is in the spirit of the law and economics literature. It is perfectly conceivable though that the sequence of decisions is reversed. We consider such an alternative setting where the technology is chosen ex ante in Section 3.3 below.

${ }^{14}$ Examples include the installment of anti-shoplifting devices or the use of digital rights management systems.
} 
two-stage game: In stage 1, the firm commits to a level of technical protection, reflected by the evasion cost $k$. Establishing the level of protection $k$ requires an investment $F_{k}(k)$. In stage 2, the firm chooses the price $p$ and the fine $f$, subject to the constraints $p>0$ and $0 \leq f \leq \bar{f}$. Specifically, the firm's choice of technological protection solves

$$
\max _{k \geq 0} \Pi(k)=\left(p^{*}(\bar{f}, k)-c\right) D^{*}(\bar{f}, k)+(\pi \bar{f}-c) E^{*}(\bar{f}, k)-F-F_{k}(k),
$$

where $p^{*}(\bar{f}, k), D^{*}(\bar{f}, k) \equiv D\left(p^{*}(\bar{f}, k), \bar{f}\right)$, and $E^{*}(\bar{f}, k) \equiv E\left(p^{*}(\bar{f}, k), \bar{f}\right)$ follow from the second-stage problem described in Section 3.1. We assume that the cost of the protection technology $F_{k}(k)$ is strictly convex, with $F_{k}(0)=0$.

Clearly, the optimal choice of technical protection depends on the functional form of the cost function $F_{k}(k)$. Now, if the solution to problem (8), denoted as $k^{*}$, exceeds $\bar{k}$, a level of $k$ so high that evading payment is "too costly," payment evasion is prevented endogenously by means of technical protection. For $k^{*}<\bar{k}$, there remains some level of payment evasion, which is detected with probability $\pi$.

\section{Illustrative Example}

We now illustrate our above analysis with an example where the consumers' indirect utility functions are explicitly specified. For simplicity, we set $N$ equal to unity and assume that consumer types $\theta$ are drawn independently from a uniform distribution over the interval $[0,1]$. In addition, we assume that consumers have rational expectations about the actual detection probability and set $\phi=\pi$.

Suppose that the conditional indirect utility functions are given by $v_{P}(p ; \theta)=\theta s_{P}-p$ and $v_{E}(f ; \theta, \pi, k)=\theta s_{E}-\pi f-k$. The parameters $s_{P}$ and $s_{E}$ denote the overall quality experience when the product is obtained with payment and evading payment, respectively. Assumption 1 requires that $s_{P}>s_{E}$, which reflects the idea that the consumers have to bear up against being detected and exposed as payment evaders.

Assumption 1 imposes that $\underline{\theta}(f) \leq \bar{\theta}(p, f)$, thereby restricting the evasion cost to be sufficiently small in order for payment evasion to occur:

$$
k \leq \frac{p s_{E}-\pi f s_{P}}{s_{P}} \equiv \bar{k}
$$

For $\bar{k}$ to be a positive number, we assume that $\frac{s_{P}}{p}<\frac{s_{E}}{\pi f}$, that is, the quality per dollar of a purchase is lower than the quality per dollar when evading payment. The demand of paying consumers and the demand for the outside option are now given by

$$
D(p, f ; \pi, k)=1-\frac{p-\pi f-k}{s_{P}-s_{E}} \text { and } \quad X(f ; \pi, k)=\frac{\pi f+k}{s_{E}},
$$


respectively, and payment evasion can be derived as

$$
E(p, f ; \pi, k)=\frac{p s_{E}-s_{P}(\pi f+k)}{\left(s_{P}-s_{E}\right) s_{E}} .
$$

It can be checked that the demand functions satisfy Assumptions 2 and 3. In addition, notice that the demand for the outside option does not depend on the price $p$. The next result illustrates the key results derived in Propositions 1 to 4.

Corollary 1. Suppose that $k \leq \frac{\left(s_{P}-s_{E}\right)\left(s_{E}-2 \pi \bar{f}\right)}{2 s_{P}-s_{E}}$. Then, $(i)$ the optimal price and fine are given by

$$
p^{*}=\pi \bar{f}+\frac{s_{P}-s_{E}+k}{2} \quad \text { and } \quad f^{*}=\bar{f}
$$

(ii) the price $p^{*}$ increases in the maximum fine $\bar{f}$ and the cost of evading payment $k$; (iii) at the optimum, payment evasion is given by

$$
E^{*}(\bar{f}, k)=\frac{1}{2}-\frac{\pi \bar{f}}{s_{E}}-\frac{\left(2 s_{P}-s_{E}\right) k}{2\left(s_{P}-s_{E}\right) s_{E}}
$$

and it decreases in $\bar{f}$ and $k$; and (iv) the optimized profit $\Pi^{*}(\bar{f}, k)$ increases in $\bar{f}$ and $k$.

Let us now compare our analysis to the standard monopoly model where nonpaying consumers are excluded by assumption. Corollary 1 shows that if the consumers' evasion cost is prohibitively high $(k=\bar{k})$, there is indeed no payment evasion, and therefore $E^{*}(\bar{f}, \bar{k})=0$. In this case, consumers are either willing to pay the price or they refrain from consumption, as in the standard monopoly model. The key difference is that, in our setting, some of the nonpaying consumers are optimally not excluded for $k<\bar{k}$. In this case, payment evasion is endogenously determined by (9).

\section{Empirical Evidence}

In this section, we examine payment evasion on the Zurich Transport Network (ZVV), where evading payment is equivalent to fare dodging. This part of our analysis is related to earlier empirical work on fare dodging in public transportation (Kooreman 1993) and digital piracy in the music and movie industry (Rob and Waldfogel 2006, Zentner 2006, Oberholzer-Gee and Strumpf 2007, Rob and Waldfogel 2007, Waldfogel 2012a, Peukert et al. 2013). ${ }^{15}$ In contrast to the extensive literature on the impact of public enforcement on unlawful behavior (see, e.g., Levitt 1997, DiTella and Schargrodsky 2004, DeAngelo

\footnotetext{
${ }^{15}$ Waldfogel (2012b) provides a comprehensive survey on the empirics of digital piracy.
} 
and Hansen 2014), we focus on the private enforcement by the ZVV, exploiting passengerlevel data over a period of four years, extending from June 1, 2009 to May 31, 2013.

We first give a brief description of the transportation company and the structure of the fines it collects from detected payment evaders. Then, we compare the characteristics of all passengers who use public transportation with those of payment evaders, using census data and individual-level data from the ZVV. Next, we estimate the amount of payment evasion on the transport network. Finally, we study the impact of an exogenous change in the maximum admissible fines on the amount of payment evasion.

\subsection{Transportation Company}

The ZVV is a public transportation company that coordinates more than 50 operators and offers railroad, bus, tram, and boat services in Zurich and its surrounding regions. ${ }^{16}$ The monopoly network carries about 570 million passengers a year and it is set up as an 'openaccess' transportation system, allowing passengers to board any means of transportation without prior ticket inspection.

The ZVV chooses the ticket prices and the fines for passengers who are detected as payment evaders. The fines set by the ZVV are not allowed to exceed the maximum admissible fines prescribed by the national industry association for public transportation (Verband öffentlicher Verkehr, VöV). Specifically, the ZVV chooses the following fines: Passengers who fail to present a valid ticket are required to prove their identity and to pay CHF 80 (about \$85) in the case of a first offense. The fine for the second offense within two years is CHF 120 (about \$125). In the case of a third offense (or more than three offenses), the fine increases to CHF 150 (about \$160), but there are no criminal charges pressed. ${ }^{17}$ Table 1 summarizes the fines, and provides the changes of the fines implemented on June 1, 2011. The relevant fines for evading payment are posted highly visibly at all stops, as well as in the entry area and on the windows of all means of transportation.

The personal information collected from payment evaders is stored in a data pool operated by the ZVV. This allows the ZVV to identify repeat offenders (who potentially use different operators within the transport network) and to construct the two-year time window during which higher fines apply. The personal information includes the address, gender, nationality, and date and place of birth. Data privacy acts require that the ZVV

\footnotetext{
${ }^{16}$ The ZVV is owned by participating municipalities and the Canton of Zurich, a member state of the federal state of Switzerland.

${ }^{17}$ Additional charges apply for noncooperative behavior in ticket inspections, giving incorrect personal information, and for forging tickets (which may lead to criminal prosecution).
} 
Table 1: Fines for Traveling Without a Valid Ticket.

\begin{tabular}{lrrr}
\hline & Before June 1, 2011 & After June 1, 2011 & Change \\
\hline First offense & 80 & 100 & $25.0 \%$ \\
Second offense* & 120 & 140 & $16.7 \%$ \\
Three and more offenses* $^{*}$ & 150 & 170 & $13.3 \%$ \\
\hline
\end{tabular}

Notes: Fines in Swiss Francs (CHF); The fines consist of a surcharge for traveling without a valid ticket and a flat fare amount to cover the lost revenue; ${ }^{*}$ : Higher fines apply within a two-year time window from the last offense.

deletes the records of passengers from the data pool who are not repeatedly caught within two years after payment.

\subsection{Passengers}

The characteristics of passengers who use the ZVV transport network are obtained from a sample constructed from 2010 census data on transportation and mobility. ${ }^{18}$ This indirect approach using census data is necessary to construct a reference group, since the ZVV solely collects data on detected payment evaders. Table 2 provides descriptive statistics for the reference group (the 0-group). The characteristics listed match those kept on record by the ZVV for payment evaders.

The characteristics of payment evaders are obtained from a sample constructed from data provided by the ZVV which covers the time span June 1, 2009 to May 31, 2013. ${ }^{19}$ A unique feature of the data is that it includes all passengers who have been detected as payment evaders during the sample period. Table 2 provides the descriptive statistics for all pre-June 2010 payment evaders (the $E$-group) and a comparison to the reference group. The next result summarizes the findings.

Finding 1 (Characteristics). Both male and young consumers are significantly overrepresented in the group of payment evaders. Among payment evaders, the degree of overrepresentation is positively related to the number of offenses.

\footnotetext{
${ }^{18}$ The census data Mikrozensus Mobilität und Verkehr 2010 is a representative study compiled by the Swiss Federal Statistical Office (see http://www.bfs.admin.ch). Detailed information about the construction of the sample is available from the authors upon request.

${ }^{19}$ The data set combines proprietary data on all detected payment evaders obtained from PostBus Switzerland Ltd (Region Zurich), the Verkehrsbetriebe Zürich (VBZ), and the Swiss Federal Railways (SBB), the operators that conduct ticket inspections on behalf of the ZVV on its transport network. Detailed information about the construction of the sample is available from the authors upon request. Constructing the merged data set was necessary because each operator has only limited access to the data pool in order to comply with data privacy acts.
} 
Table 2: Descriptive Statistics for the Different Groups.

\begin{tabular}{lrrrrrrrrr}
\hline Variable & \multicolumn{3}{c}{ Comparison of groups } & & \multicolumn{3}{c}{ Breakdown of $E$-group } \\
\cline { 2 - 3 } \cline { 8 - 10 } Mean, values in \% & 0-group & $E$-group & $p$-value & & 1 & $2-3$ & $4-7$ & $8+$ \\
\hline Men & 48 & 57 & 0.00 & & 55 & 63 & 73 & 75 \\
Age in years (mean) & 39 & 31 & 0.00 & & 32 & 29 & 28 & 28 \\
Nationality: & & & & & & & & \\
Swiss & 64 & 63 & 0.24 & & 65 & 62 & 62 & 59 \\
German & 10 & 6 & 0.00 & & 6 & 5 & 3 & 5 \\
Italian & 6 & 3 & 0.00 & & 3 & 3 & 4 & 4 \\
Western Europe* & 9 & 6 & 0.00 & & 6 & 6 & 5 & 4 \\
Eastern Europe & 1 & 2 & 0.10 & & 2 & 2 & 2 & 1 \\
Former Yugoslavia & 4 & 5 & 0.01 & & 4 & 6 & 7 & 8 \\
Turkish & 1 & 2 & 0.09 & & 2 & 2 & 2 & 3 \\
Africa & 1 & 4 & 0.00 & & 3 & 5 & 8 & 7 \\
Asia & 2 & 3 & 0.00 & & 3 & 3 & 3 & 6 \\
South America & 2 & 2 & 0.39 & & 2 & 3 & 2 & 2 \\
\hline Other violations $(0 / 1)$ & - & 1.1 & - & & 1.1 & 1.2 & 1.4 & 0.6 \\
Amount in CHF & - & 120 & - & 108 & 155 & 191 & 190 \\
\hline Sample size & 3,734 & 112,872 & - & 90,396 & 18,061 & 3,337 & 1,078 \\
\hline
\end{tabular}

Notes: All individuals have a permanent address in Switzerland; The reference group consists of a representative sample of passengers (0-group), among them some evaders, and the group of payment evaders ( $E$-group) consists of all pre-June 2010 evaders; $p$-value of 2-sample $t$-test for mean differences of group 0 and group $E$; Repeat offenders: 1, 2-3, 4-7, and 8 and more offenses (8+) by the same individual; *: Other Western Europe, including the USA, Canada, Australia, and New Zealand. 'Other violations' is an indicator of whether the fare evasion was associated with some other violation (e.g., attempting to escape the ticket inspections or using forged tickets).

Finding 1 is consistent with previous studies on crime (DiIulio 1996) and-more closely related —on shoplifting (Cox et al. 1990), which report a concentration of offenses among young males.

Table 2 offers additional insights. First, breaking down payment evaders according to their nationalities reveals that some groups are underrepresented, while other groups appear to be overrepresented. Second, roughly $20 \%$ of the payment evaders are caught repeatedly. This is quite remarkable, notably because the detection probability is as low as $1.4 \%$ (see Table 3 ). In addition, on average, $1.1 \%$ of the payment evaders commit other violations, such as attempting to escape the ticket inspections or using forged tickets. This results in additional fees, as reflected by the average amounts charged. 
Table 3: Quantifying Payment Evasion and Deterrence.

\begin{tabular}{lrrr}
\hline & Before June 1, 2011 & After June 1, 2011 & Change (\%) \\
\hline Paying passengers $(D)$ & $46,751,476$ & $48,411,632$ & 3.6 \\
Payment evaders $(\hat{E})$ & 618,522 & 727,839 & 17.7 \\
Detection probability $(\hat{\pi})$ & 0.0139 & 0.0127 & -8.6 \\
Deterrence level $(\hat{\pi} f)$ & & & \\
First offense & 1.11 & 1.27 & 14.4 \\
Second offense & 1.66 & 1.78 & 7.2 \\
Third offense & 2.08 & 2.16 & 3.8 \\
Cheapest ticket price $(p)$ & 2.20 & 2.20 & - \\
\hline
\end{tabular}

Notes: Averages based on monthly data; The estimated payment evasion $\hat{E}$ is equal to the number of detected payment evaders $\tilde{E}$ divided by the estimated detection probability $\hat{\pi}$; The estimated detection probability is equal to the number of detected payment evaders divided by the number of inspected passengers; Expected fines in Swiss Francs (CHF), obtained by multiplying the estimated detection probability with the relevant fine.

\subsection{Payment Evasion}

Tickets inspections on the ZVV network are unannounced and conducted by plain-clothes agents. The agents board a selected public service vehicle and require all passengers to present a valid ticket. Those passengers who fail to present a valid ticket must reveal their identity, and their personal data are electronically recorded by the agents. In addition, the ZVV records the number of passengers who are controlled in ticket inspections. We use these data to construct an estimate of the detection probability $\hat{\pi}$ by dividing the number of detected payment evaders through the number of passengers checked. Next, we use $\hat{\pi}$ and the number of detected payment evaders $\tilde{E}$ to estimate the total amount of payment evasion as $\hat{E}=\tilde{E} / \hat{\pi}$, which is the empirical counterpart of payment evasion $E$ in the theoretical model (see Definition 1).

Table 3 summarizes these estimates and provides the relevant deterrence levels for first-time and repeat offenses. It is worth noting that even the lowest available ticket price is higher than any of the expected fines, a necessary condition for payment evasion to occur (consistent with Proposition 1). The next result shows that payment evasion is indeed not fully deterred.

Finding 2 (Underdeterrence). The ZVV consistently sets the maximum admissible fines, inspects its passengers with an endogenously chosen detection probability, and faces considerable payment evasion.

Finding 2 shows that the transportation company does not fully deter payment evasion. Our theoretical analysis suggests two reasons: First, the given maximum admissible fines 


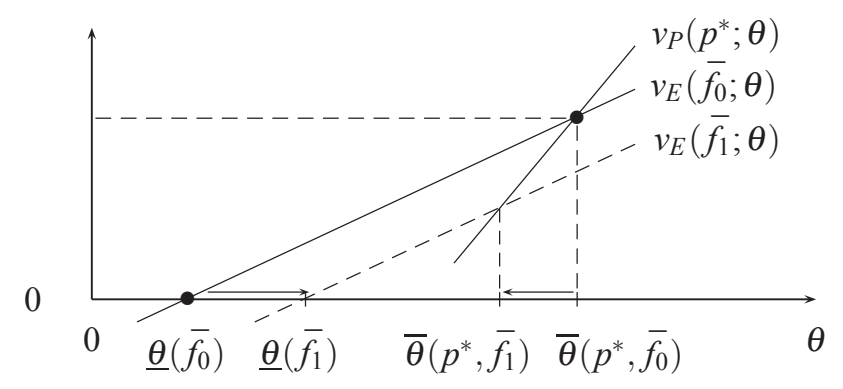

Figure 2: Deterrence Effect of a Higher Fine.

are too small. Second, further increasing the detection probability through higher effort is too costly.

\subsection{Increase in Maximum Admissible Fines}

The industry association for public transportation allowed its members to charge higher maximum fines for payment evasion starting from June 1, 2011. This opportunity was immediately seized by the ZVV (Finding 2). According to our model, the increase in fines should have reduced payment evasion unambiguously, as the ticket prices were approximately held constant during the time of observation (see Proposition 3).

We exploit this exogenous variation over time to study the impact of higher fines on payment evasion. In doing so, we employ data on the universe of passengers detected as payment evaders during the time of observation. Specifically, we estimate the aggregate effect on payment evasion, as well as the disaggregated effects across different types of payment evaders. To this end, we derive the following hypothesis.

Hypothesis 1. Suppose the price is fixed at $p_{0}$, and consider an increase in the fine from $\bar{f}_{0}$ to $\bar{f}_{1}$. Then, the number of detected payment evaders decreases, and the aggregate change can be decomposed into type-specific changes as follows:

$$
\tilde{E}\left(p_{0}, \bar{f}_{1}\right)-\tilde{E}\left(p_{0}, \bar{f}_{0}\right)=-\pi N\left[\int_{\bar{\theta}\left(p_{0}, \bar{f}_{1}\right)}^{\overline{\boldsymbol{\theta}}\left(p_{0}, \bar{f}_{0}\right)} g(\boldsymbol{\theta}) d \boldsymbol{\theta}+\int_{\underline{\boldsymbol{\theta}}\left(\bar{f}_{0}\right)}^{\underline{\theta}\left(\bar{f}_{1}\right)} g(\boldsymbol{\theta}) d \boldsymbol{\theta}\right] .
$$

Hypothesis 1 predicts how the type-specific effects aggregate across payment evaders: Some high-type evaders are induced to pay the price, while some low-type evaders are induced to refrain from consumption, as illustrated in Figure 2. Clearly, the reduction of payment evasion depends on the mass of consumers in the relevant regions of the density function. 


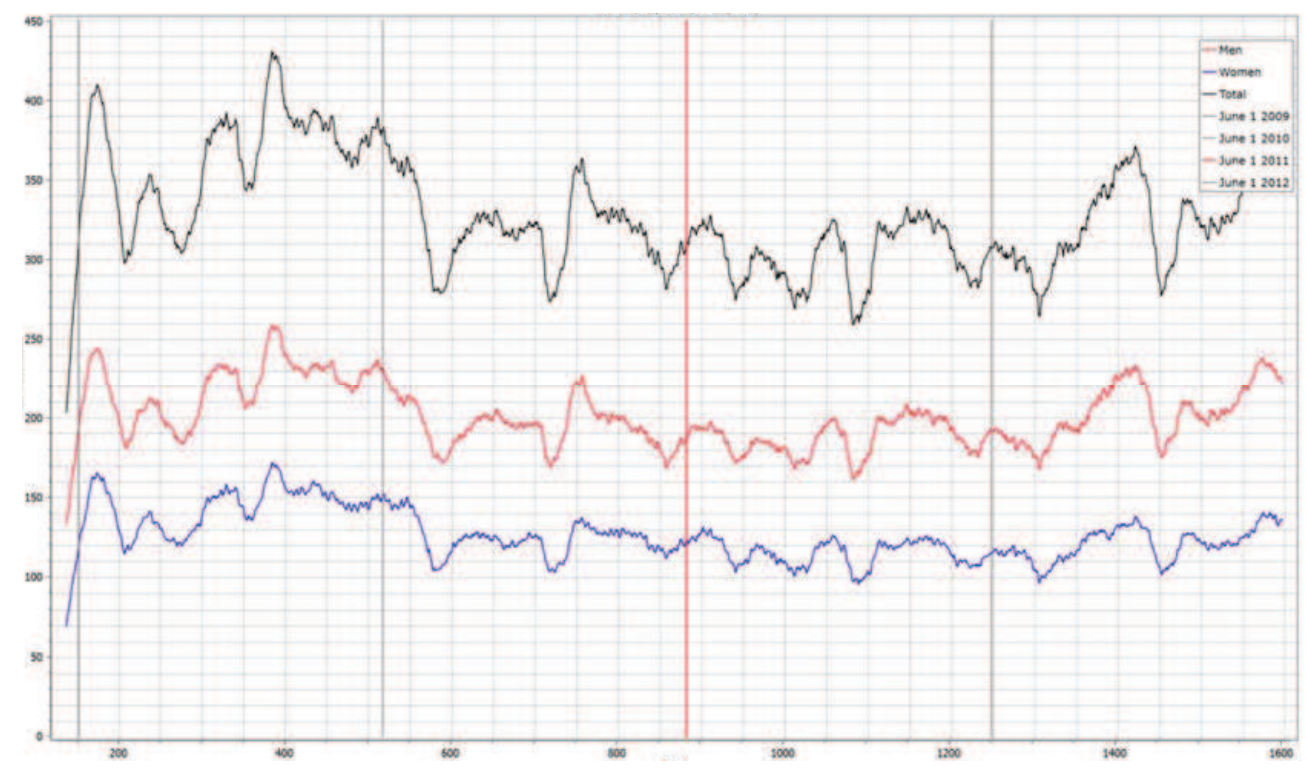

Notes: Thirty-day moving average of the daily number of detected payment evaders; The sample period covers June 1, 2009 to May 31, 2013.

Figure 3: Number of Detected Payment Evaders, Total and by Gender.

We first look at the evolution of the aggregate number of detected payment evaders over time. Figure 3 covers the time period June 1, 2009 through May 31, 2013 and plots thirty-day moving averages (the fines are adjusted in the middle of the sample period). Inspection of the figure yields the following result.

Finding 3 (Aggregate Effect). The higher maximum admissible fines do not reduce the number of detected payment evaders.

Next, we look at the evolution of the number of payment evaders by type. To do so, we let payment evaders self-select into different subgroups, based on their individual offense history. The self-selection period runs from June 1, 2009 to May 31, 2010. The choice of this period ensures that the selection process is arguably unaffected by the change in fines. In order to have a sufficiently large number of observations in each subgroup, we assign each detected payment evader to one of the following four groups: one offense (1), two and three offenses (2-3), four to seven offenses (4-7), and eight and more offenses (8+).

To meaningfully assess the impact of the changes in the fines, one has to take into account that the composition of the groups differs by (exogenous) characteristics, as documented in Table 2. To eliminate the effect of these differences in characteristics, we use propensity score weighting (see, for example, DiNardo et al. 1996). Reweighting is 


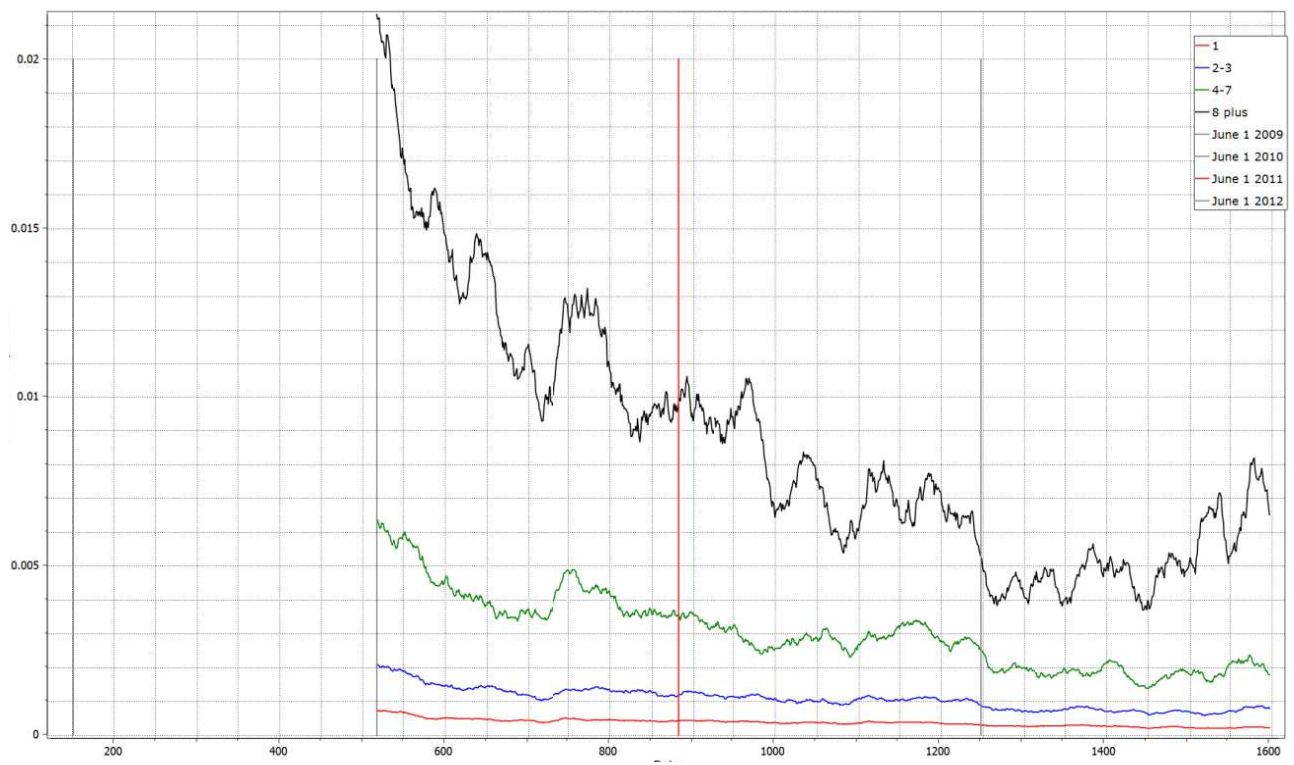

Notes: Thirty-day moving average of the number of detected payment evaders by subgroup, divided by the number of members per subgroup; The sample period covers June 1, 2010 to May 31, 2013; The data covering June 1, 2009 to May 31, 2010 are used to let payment evaders self-select into subgroups of types.

Figure 4: Normalized Number of Detected Payment Evaders by Subgroup.

performed such that the distribution of all offenders is taken as the reference distribution, and the individuals in the different offense groups are reweighted accordingly. ${ }^{20}$

Using the reweighted observations, we follow the groups of pre-June 2010 offenders over time. Specifically, we count the number of payment evaders from each reference group who are repeatedly detected as payment evaders after June 1, 2010, and normalize the count data by the respective size of the reference group. This yields the group-specific offense probabilities plotted in Figure 4, which give rise to the following finding. ${ }^{21}$

\footnotetext{
${ }^{20}$ This approach is in the spirit of Horwitz and Thomson (1952). For each offender group the estimator is implemented as follows: a) Pool a particular offender group with the group of all offenders (the observations of the particular group will thus appear twice). b) Compute an indicator variable, $T_{i}$, which is one, if an observation belongs to the target population, and zero when it belongs to the particular offender population under investigation. c) Estimate a binary probit to compute $p_{i}:=P\left(T_{i}=1 \mid X=x_{i}\right)$. Covariates in this probit are age, age squared, sex, sex-age interactions, indicators for different groups of foreigner, sex-foreigner interactions, and other violations. A constant term is included as well. d) Let $w_{i}=\left(1-p_{i}\right) / p_{i}$ and normalize $w_{i}$ such that they add up to one. The mean of $y$ (e.g., the probability of an offense) among this particular group of offenders is then computed as the sum of $w_{i} y_{i}$ over all offenders of this group. The estimation results of the probit as well as a descriptive table showing that reweighting was indeed successful to balance the covariates is available from the authors upon request.

${ }^{21}$ Figure 4 deliberately assumes the control effort to be constant as in Hypothesis 1 . Accounting for the change in the control effort does not qualitatively affect the results.
} 
Finding 4 (Type-Specific Effect). Payment evaders in different groups exhibit systematic differences in offense probabilities, meaning that they differ in unobservables which are related to their individual offense histories. Yet, they do not show different reactions to higher fines.

In sum, there is no evidence for any significant effect of the higher fines on payment evasion, neither at the aggregate level nor for the different groups of types. A possible explanation is that the ZVV seized the opportunity to reduce the costly control effort without reducing the relevant deterrence levels, as suggested by Proposition 5. Table 3 suggests that the detection probability was indeed reduced accordingly.

\section{Conclusion}

This paper has examined endogenous payment evasion in a model where the firm can charge a price to paying consumers and levy a fine on consumers who are detected as payment evaders. In addition, we have provided empirical evidence on payment evasion on the Zurich Transport Network, where evading payment is equivalent to fare dodging.

In the theoretical part, we have derived three key results. First, paying consumers "overpay," as the firm charges them higher prices than in the absence of payment evaders. Specifically, the presence of payment evaders leads to a peculiar form of price discrimination where the regular price exceeds the expected fine. Second, the firm has no incentive to fully deter payment evasion as it can generate a higher profit, provided that a sufficiently efficient detection technology is available. Third, higher fines do not necessarily reduce payment evasion.

In the empirical part, we have reported evidence that is consistent with our theoretical analysis, using firm-level and passenger-level data. We have constructed the empirical counterparts of the relevant quantities in the theoretical model, and we have found that the exogenous increase in the maximum admissible fines did not have a significant effect on payment evasion.

Our analysis suggests several avenues for future research. First, one could generalize our analysis to a fully dynamic setting where consumers repeatedly decide whether or not to evade payment. Second, one could extend the analysis to allow for competition among firms to study the role of payment evasion as a particular form of non-price competition. We hope to address these issues in future research. 


\section{Appendix A The Relationship between Preferences and Demand}

This appendix links the properties of the demand of paying consumers and the demand for the outside option to the properties of the underlying conditional indirect utility functions. To simplify the exposition, we conveniently suppress the arguments of the functions.

Utility Foundation for Assumption 2. Recall that the demand of paying consumers is given by

$$
D(p, f ; \phi, k)=N[1-G(\overline{\boldsymbol{\theta}}(p, f ; \phi, k))] .
$$

(i) The demand of paying consumers decreases in price $p$ provided that

$$
\frac{\partial D}{\partial p}=-N g(\bar{\theta}) \frac{\partial \bar{\theta}}{\partial p}<0
$$

where

$$
\frac{\partial \bar{\theta}}{\partial p}=-\frac{\frac{\partial}{\partial p} v_{P}}{\frac{\partial}{\partial \theta}\left(v_{P}-v_{E}\right)}
$$

results from applying the implicit function theorem to the indifference condition $v_{P}(p ; \bar{\theta})=$ $v_{E}(f ; \bar{\theta}, \phi)$, which defines $\bar{\theta}$. As $g(\theta)>0$ for all $\theta$ and since the denominator of the right-hand side of (A.1) is positive by Assumption 1, demand decreases in price $p$ if and only if $\partial v_{P} / \partial p<0$, that is, if and only if the indirect utility of obtaining the product with payment decreases in price. (ii) The demand of paying consumers increases in the fine $f$ provided that

$$
\frac{\partial D}{\partial f}=-N g(\bar{\theta}) \frac{\partial \bar{\theta}}{\partial f}>0
$$

where

$$
\frac{\partial \bar{\theta}}{\partial f}=\frac{\frac{\partial}{\partial f} v_{E}}{\frac{\partial}{\partial \theta}\left(v_{P}-v_{E}\right)} .
$$

Using Assumption 1, demand increases in the fine $f$ if and only if $\partial v_{E} / \partial f<0$, that is, if and only if the indirect utility of obtaining the product evading payment decreases in the fine. (iii) The demand of paying consumers increases in the evasion cost $k$ provided that

$$
\frac{\partial D}{\partial k}=-N g(\bar{\theta}) \frac{\partial \bar{\theta}}{\partial k}>0
$$

where

$$
\frac{\partial \bar{\theta}}{\partial k}=\frac{\frac{\partial}{\partial k} v_{E}}{\frac{\partial}{\partial \theta}\left(v_{P}-v_{E}\right)} .
$$

Using Assumption 1, demand increases in the evasion costs $k$ if and only if $\partial v_{E} / \partial k<0$, that is, if and only if the indirect utility of obtaining the product evading payment decreases in the evasion costs. (iv) The demand of paying consumers is concave in price $p$ provided that

$$
\frac{\partial^{2} D}{\partial p^{2}}=-N\left[g^{\prime}(\bar{\theta})\left(\frac{\partial \bar{\theta}}{\partial p}\right)^{2}+g(\bar{\theta}) \frac{\partial^{2} \bar{\theta}}{\partial p^{2}}\right] \leq 0,
$$


where

$$
\frac{\partial^{2} \bar{\theta}}{\partial p^{2}}=-\frac{\frac{\partial^{2}}{\partial p^{2}} v_{P} \frac{\partial}{\partial \theta}\left(v_{P}-v_{E}\right)-\frac{\partial}{\partial p} v_{P} \frac{\partial^{2}}{\partial p \partial \theta}\left(v_{P}-v_{E}\right)}{\left(\frac{\partial}{\partial \theta}\left(v_{P}-v_{E}\right)\right)^{2}}
$$

Obviously, the sign of (A.3) is not readily determined. To unambiguously sign the expression, we below further restrict the density function and the indirect utility functions. (v) The demand of paying consumers satisfies $\partial^{2} D /(\partial f \partial p) \geq 0$ if and only if

$$
\frac{\partial^{2} D}{\partial f \partial p}=-N\left[g^{\prime}(\bar{\theta}) \frac{\partial \bar{\theta}}{\partial f} \frac{\partial \bar{\theta}}{\partial p}+g(\bar{\theta}) \frac{\partial^{2} \bar{\theta}}{\partial f \partial p}\right] \geq 0,
$$

where

$$
\frac{\partial^{2} \bar{\theta}}{\partial f \partial p}=-\frac{\frac{\partial^{2}}{\partial f \partial p} v_{P} \frac{\partial}{\partial \theta}\left(v_{P}-v_{E}\right)-\frac{\partial}{\partial p} v_{P} \frac{\partial^{2}}{\partial f \partial \theta}\left(v_{P}-v_{E}\right)}{\left(\frac{\partial}{\partial \theta}\left(v_{P}-v_{E}\right)\right)^{2}}
$$

(vi) The demand of paying consumers satisfies $\partial^{2} D /(\partial k \partial p) \geq 0$ if and only if

$$
\frac{\partial^{2} D}{\partial k \partial p}=-N\left[g^{\prime}(\bar{\theta}) \frac{\partial \bar{\theta}}{\partial k} \frac{\partial \bar{\theta}}{\partial p}+g(\bar{\theta}) \frac{\partial^{2} \bar{\theta}}{\partial k \partial p}\right] \geq 0,
$$

where

$$
\frac{\partial^{2} \bar{\theta}}{\partial k \partial p}=-\frac{\frac{\partial^{2}}{\partial k \partial p} v_{P} \frac{\partial}{\partial \theta}\left(v_{P}-v_{E}\right)-\frac{\partial}{\partial p} v_{P} \frac{\partial^{2}}{\partial k \partial \theta}\left(v_{P}-v_{E}\right)}{\left(\frac{\partial}{\partial \theta}\left(v_{P}-v_{E}\right)\right)^{2}} .
$$

Collecting the insights from steps (i)-(vi) allows us to rephrase Assumption 2 in terms of the properties of the underlying conditional indirect utility functions:

Assumption 4 (Utility Foundation Demand). (i) The indirect utility functions $v_{E}(f ; \theta, \phi, k)$ and $v_{P}(p ; \theta)$ decrease in $f$ and $p$, respectively. (ii) The function $v_{E}(f ; \theta, \phi, k)$ decreases in $k$. (iii) The density function $g(\theta)$ and the cut-off value $\bar{\theta}(p, f ; \phi, k)$ jointly satisfy the conditions (A.3) through (A.5).

As the next result shows, demand has the required properties under reasonable assumptions:

Observation 1. Suppose that (i) the functions $v_{P}(p ; \theta)$ and $v_{E}(f ; \theta, \phi, k)$ are, respectively, linear in $p$ and $f$, (ii) $v_{E}(f ; \theta, \phi, k)$ is linear in $k$, (iii) the type $\theta$ does not interact with $p$, $f$, and $k$, and (iv) types are drawn from a uniform distribution. Then, the demand of paying consumers satisfies Assumption 2.

If the uniform assumption is relaxed, demand satisfies Assumption 2 if and only if $g^{\prime}(\bar{\theta}) \geq 0$. For instance, this condition holds for the family of left-skewed Beta distributions. ${ }^{22}$

\footnotetext{
${ }^{22}$ Recall that this family includes the uniform distribution over the unit interval as a special case.
} 
Utility Foundation for Assumption 3. Recall that the demand for the outside option is given by

$$
X(f ; \phi, k)=N[G(\underline{\theta}(f ; \phi, k))] .
$$

(i) The demand for the outside option is increasing in the fine $f$ provided that

$$
\frac{\partial X}{\partial f}=N g(\underline{\theta}) \frac{\partial \underline{\theta}}{\partial f}>0
$$

which automatically holds as

$$
\frac{\partial \underline{\theta}}{\partial f}=-\frac{\frac{\partial}{\partial f} v_{E}}{\frac{\partial}{\partial \theta} v_{E}}>0
$$

by Assumption $4 .{ }^{23}$ (ii) The proof that $X$ is increasing in $k$ is similar and therefore omitted.

\section{Appendix B Proofs}

This appendix reports the proofs of our results.

Proof of Lemma 1. Suppose that $p>\pi f$. The first-order condition in (5) admits for an interior solution for $f$ only if

$$
\frac{\partial X(f)}{\partial f} \geq \frac{(p-\pi f) \frac{\partial D}{\partial f}+\pi(N-D(p, f)-X(f))}{\pi f-c}
$$

for some $(p, f)$. Conversely, if $p \leq \pi f$, the first-order condition in (4) shows that there is no interior solution for $p$.

Proof of Proposition 1. If $f^{*}=\bar{f}, p^{*}(\bar{f}, k)$ is determined by the first-order condition in (4), which can be restated as

$$
\frac{p^{*}-\pi \bar{f}}{p^{*}}=\frac{1}{\varepsilon_{p}},
$$

where $\varepsilon_{p} \equiv-(\partial D / \partial p)(p / D)$ denotes the price elasticity of demand. Subtracting $c / p^{*}$ on both sides of (B.2) and rearranging yields the result.

Proof of Proposition 2. If $f^{*}=\bar{f}, p^{*}(\bar{f}, k)$ is determined by (4). (i) The comparative statics effect of $\bar{f}$ on the optimal price $p^{*}$ is readily determined by applying the implicit function theorem to the first-order condition in (4) evaluated at $\bar{f}$ :

$$
\frac{d p^{*}(\bar{f}, k)}{d \bar{f}}=-\frac{\frac{\partial D}{\partial f}+\left(p^{*}-\pi \bar{f}\right) \frac{\partial^{2} D}{\partial f \partial p}-\pi \frac{\partial D}{\partial p}}{2 \frac{\partial D}{\partial p}+\left(p^{*}-\pi \bar{f}\right) \frac{\partial^{2} D}{\partial p^{2}}}
$$

\footnotetext{
${ }^{23}$ Notice that (A.7) follows from applying the implicit function theorem to the indifference condition $\nu_{E}(f ; \bar{\theta}, \phi, k)=0$, which defines $\underline{\theta}$.
} 
Recall from Proposition 1 that $p^{*}-\pi \bar{f}>0$. The claim is established using the properties of the demand function in Assumption 2. (ii) The comparative statics effect of $k$ on the optimal price $p^{*}$ can be derived as

$$
\frac{d p^{*}(\bar{f}, k)}{d k}=-\frac{\frac{\partial D}{\partial k}+\left(p^{*}-\pi \bar{f}\right) \frac{\partial^{2} D}{\partial k \partial p}}{2 \frac{\partial D}{\partial p}+\left(p^{*}-\pi \bar{f}\right) \frac{\partial^{2} D}{\partial p^{2}}},
$$

which is again positive using the same argument as in part (i). This establishes the claim.

Proof of Proposition 3. At the optimum, payment evasion is given by $E^{*}(\bar{f}, k) \equiv E\left(p^{*}(\bar{f}, k), \bar{f} ; k\right)$. Totally differentiating $E^{*}(\bar{f}, k)$ produces

$$
\frac{d E^{*}(\bar{f}, k)}{d \kappa}=\frac{\partial E}{\partial p} \frac{d p^{*}(\bar{f}, k)}{d \kappa}+\frac{\partial E}{\partial \kappa}
$$

where $\kappa \in\{\bar{f}, k\} . E^{*}(\bar{f}, k)$ decreases in response to an increase in $\kappa$ if and only if

$$
\begin{aligned}
\frac{d p^{*}(\bar{f}, k)}{d \kappa} & <-\frac{\partial E / \partial \kappa}{\partial E / \partial p} \\
& =-\frac{\partial D / \partial \kappa+\partial X / \partial \kappa}{\partial D / \partial p}
\end{aligned}
$$

where the equality uses Definition 1. Consequently, payment evasion decreases if and only if the corresponding price increase is not too large.

Proof of Proposition 4. The optimized profit is given by $\Pi^{*}(\bar{f}, k) \equiv \Pi\left(p^{*}(\bar{f}, k), \bar{f} ; k\right)$. By the envelope theorem, the effect on $\Pi^{*}(\bar{f}, k)$ of a change in $p^{*}(\bar{f}, k)$ is of the second order. Hence, for $\kappa \in\{\bar{f}, k\}$,

$$
\frac{d \Pi\left(p^{*}(\bar{f}, k), \bar{f} ; k\right)}{d \kappa}=\frac{\partial \Pi\left(p^{*}, \bar{f}\right)}{\partial \kappa} .
$$

(i) For $\kappa=\bar{f}, \partial \Pi / \partial \bar{f}>0$ by (B.1); if this condition were not satisfied, there would be no corner solution for $f$. (ii) For $\kappa=k, \partial \Pi / \partial k>0$ if and only if

$$
\frac{\partial X / \partial k}{\partial D / \partial k}<\frac{p-\pi \bar{f}}{\pi \bar{f}-c}
$$

Consequently, the profit increases in the evasion cost if the ratio of consumers who are driven out of the market to diverted consumers is not too large; otherwise, the profit decreases in $k$.

Proof of Proposition 5. (i) In the second stage, for given $(p, f)$, the firm solves

$$
\max _{e \geq \underline{e}} \Pi(e ; p, f)=(p-c) D(p, f)+(\pi(e) f-c) E(p, f)-F-F_{\pi}(e) .
$$

At an interior solution, the optimal effort $e^{*}(p, f)$ solves

$$
\pi^{\prime}\left(e^{*}(p, f)\right) f E(p, f)-F_{\pi}^{\prime}\left(e^{*}(p, f)\right)=0 .
$$


Substituting $e^{*}(p, f)$ back into the profit function, the firm solves

$$
\max _{p, f} \Pi(p, f)=(p-c) D(p, f)+\left(\pi\left(e^{*}(p, f)\right) f-c\right) E(p, f)-F-F_{\pi}\left(e^{*}(p, f)\right)
$$

subject to the constraints $p>0$ and $0 \leq f \leq \bar{f}$ in the first stage. Applying the envelope theorem, the first-order condition for $p$ at the constrained optimum is

$$
\frac{\partial \Pi}{\partial p}=D+\left(p-\pi\left(e^{*}\right) \bar{f}\right) \frac{\partial D}{\partial p}=0,
$$

which can be rearranged as (7) using the same logic as in the proof of Proposition 1. Denoting the solution to (B.7) as $p^{*}(\bar{f})$, the implied optimal effort $e^{*}(\bar{f}) \equiv e^{*}(p(\bar{f}), \bar{f})$ follows from (B.6) by substitution. Further substituting the optimal effort level $e^{*}$ into $\pi(e)$ and $F_{\pi}(e)$ yields $\pi\left(e^{*}\right)$ and $F_{\pi}\left(e^{*}\right)$. (ii) Applying the implicit function theorem to (B.7) yields

$$
\frac{d p^{*}}{d \bar{f}}=-\frac{\frac{\partial D}{\partial f}-\left[\pi^{\prime} \frac{d e^{*}}{d f} \bar{f}+\pi\right] \frac{\partial D}{\partial p}+(p-\pi \bar{f}) \frac{\partial^{2} D}{\partial f \partial p}}{[-]},
$$

where [-] indicates a negative expression (the negativity follows from the second-order condition). Using Assumption 2, the numerator is positive provided that $\frac{d e^{*}}{d f}>0$ (which is clearly an overly strong condition). Applying the implicit function theorem again, this time to (B.6), produces

$$
\begin{aligned}
\frac{d e^{*}}{d f} & =-\frac{\pi^{\prime}\left(e^{*}\right)\left(E(p, f)+f \frac{\partial E(p, f)}{\partial f}\right)}{\pi^{\prime \prime}\left(e^{*}\right) f E(p, f)-F_{\pi}^{\prime \prime}\left(e^{*}\right)} \\
& =-\frac{\pi^{\prime}\left(e^{*}\right) E(p, f)\left(1-\varepsilon_{f}\right)}{\pi^{\prime \prime}\left(e^{*}\right) f E(p, f)-F_{\pi}^{\prime \prime}\left(e^{*}\right)},
\end{aligned}
$$

which is positive as long as $\varepsilon_{f}<1$. Given the assumed properties of $\pi(e)$ and $F_{\pi}(e)$, it follows that the detection probability $\pi\left(e^{*}\right)$ and the effort cost $F_{\pi}\left(e^{*}\right)$ increase in $\bar{f}$.

Proof of Corollary 1. (i) The firm makes its decisions about the price and the fine so as to maximize

$$
\max _{p, f} \Pi(p, f)=(p-c)\left(1-\frac{p-\pi f-k}{s_{P}-s_{E}}\right)+(\pi f-c)\left(\frac{p s_{E}-s_{P}(\pi f+k)}{s_{E}\left(s_{P}-s_{E}\right)}\right)
$$

subject to the constraints $p>0$ and $0 \leq f \leq \bar{f}$. Partially differentiating the profit function with respect to $f$ yields

$$
\frac{\partial \Pi(p, f)}{\partial f}=\frac{\pi\left(2\left(p s_{E}-\pi f s_{P}\right)+c\left(s_{P}-s_{E}\right)-s_{P} k\right)}{s_{E}\left(s_{P}-s_{E}\right)},
$$

which is strictly positive as $\bar{f}<\frac{s_{n}}{2 \pi}$. This implies that there is no interior solution for $f$ and the optimal price follows from (6) in Proposition 1. (ii) The result follows by inspection of $p^{*}$ (Proposition 1). (iii) Payment evasion follows by substitution and $E^{*} \geq 0$ as long as $k \leq$ $\frac{\left(s_{P}-s_{E}\right)\left(s_{E}-2 \pi \bar{f}\right)}{2 s_{P}-s_{E}}$ (the upper bound for $k$ expresses $\bar{k}$ in terms of the model parameters). Clearly, 
$\frac{d E^{*}}{d \tilde{f}}=-\frac{\pi}{s_{E}}$ and $\frac{d E^{*}}{d k}=-\frac{2 s_{p}-s_{E}}{2 s_{E}\left(s_{P}-s_{E}\right)}$, which are both negative (Proposition 3). (iv) At the optimum, profit is given by

$$
\begin{aligned}
\Pi^{*}(\bar{f}, k)= & \frac{1}{4 s_{E}\left(s_{P}-s_{E}\right)}\left[\left(s_{P}-s_{E}+k\right)\left(s_{P}-s_{E}+2(\pi f-c)+k\right) s_{E}\right. \\
& \left.+2(\pi f-c)\left(\left(s_{P}-s_{E}\right)\left(s_{E}-2 \pi f\right)-k\left(2 s_{P}-s_{E}\right)\right)\right],
\end{aligned}
$$

and it is increasing in $\bar{f}$ provided that

$$
\frac{d \Pi^{*}}{d \bar{f}}=\frac{\pi\left(c+s_{E}-2 \pi \bar{f}-k\right)}{s_{E}}>0
$$

which holds for $k<c+s_{E}-2 \pi \bar{f} \equiv \hat{k}$. Since

$$
\hat{k}-\frac{\left(s_{P}-s_{E}\right)\left(s_{E}-2 \pi \bar{f}\right)}{2 s_{P}-s_{E}}=c+\frac{s_{P}\left(s_{E}-2 \pi \bar{f}\right)}{2 s_{P}-s_{E}}>0,
$$

the result holds for all $k \leq \bar{k}$. The profit is unambiguously increasing in $k$ as

$$
\frac{d \Pi^{*}}{d k}=\frac{\left(s_{P}-s_{E}\right)\left(s_{E}-2 \pi \bar{f}\right)+2 c\left(s_{P}-s_{E}\right)+k s_{E}}{2 s_{E}\left(s_{P}-s_{E}\right)}>0
$$

for $\bar{f}<\frac{s_{E}}{2 \pi}$ (Proposition 4).

\section{Appendix C Empirical Analysis}

This appendix provides the proof of Hypothesis 1.

Proof of Hypothesis 1. From the fundamental theorem of calculus, the overall change in payment evasion can be decomposed as

$$
\begin{aligned}
E\left(p_{0}, \bar{f}_{1}\right)-E\left(p_{0}, \bar{f}_{0}\right) & =\int_{\bar{f}_{0}}^{\bar{f}_{1}} \frac{\partial E\left(p_{0}, f\right)}{\partial f} d f \\
& =-\left[\int_{\bar{f}_{0}}^{\bar{f}_{1}} \frac{\partial D\left(p_{0}, f\right)}{\partial f} d f+\pi \int_{\bar{f}_{0}}^{\bar{f}_{1}} \frac{\partial X(f)}{\partial f} d f\right],
\end{aligned}
$$

where the second equality follows from Definition 1. Substituting the integrands in (C.1) with the corresponding expressions in (A.2) and (A.6), the change in payment evasion follows using integration by substitution. Using that $\tilde{E}=\pi E$ by construction, it follows that $\Delta \tilde{E}=\pi \Delta E$. Finally, multiplying (C.1) by $\pi$ yields establishes the claim.

\section{References}

Becker, Gary S. (1968), “Crime and Punishment: An Economic Approach,” Journal of Political Economy, 76(2), 169-217. 
Belleflamme, Paul and Martin Peitz (2014), "Digital Piracy: An Update," CORE Discussion Paper, 2014/19.

Belleflamme, Paul and Martin Peitz (2012), "Digital Piracy: Theory," in: Peitz, Martin and Joel Waldfogel (eds.), The Oxford Handbook of the Digital Economy, Oxford University Press.

Boyd, Colin, Christine Martini, John Rickard, and Allen Russell (1989), "Fare Evasion and Non-Compliance," Journal of Transport Economics and Policy, 23(2), 189-97.

Chellappa Ramnath K. and Shivendu Shivendu (2005), "Managing Piracy: Pricing and Sampling Strategies for Digital Experience Goods in Vertically Segmented Markets," Information Systems Research, 16(4), 400-17.

Chen, Yuxin, Oded Koenigsberg, and Z. John Zhang (2013), "Pay-as-You-Wish-Pricing," mimeo.

Cox, Dena, Anthongy D. Cox, and George P. Moschis (1990), "When Consumer Behavior Goes Bad: An Investigation of Adolescent Shoplifting," Journal of Consumer Research, 17(2), 149-59.

DeAngelo, Gregory and Benjamin Hansen (2014), "Life and Death in the Fast Lane: Police Enforcement and Traffic Fatalities," American Economic Journal: Economic Policy, 6(2), 231-57.

DiIulio, John J. (1990), “Help Wanted: Economists, Crime and Public Policy,” Journal of Economic Perspectives, 10(1), 3-24.

DiNardo, John, Nicole M. Fortin, and Thomas Lemieux (1996), "Labor Market Institutions and the Distribution of Wages, 1973-1992: A Semiparametric Approach," Econometrica, 64(3), 1001-44

DiTella, Rafael and Ernesto Schargrodsky (2004), "Do Police Reduce Crime? Estimates Using the Allocation of Police Forces After a Terrorist Attack," American Economic Review, 94(1), 115-33.

Ehrlich, Isaac (1996), "Crime, Punishment, and the Market for Offenses," Journal of Economic Perspectives, 10(1), 43-7.

Hirshleifer, Jack, Amihai Glazer, and David Hirshleifer (2005), Price Theory and Applications, New York, Cambridge University Press, 7th Edition.

Horvitz, Daniel G. and Donovan J. Thompson (1952), “A Generalization of Sampling without Replacement from a Finite Universe," Journal of the American Statistical Association 47(260), 663-85. 
Kooreman, Peter (1993), "Fare Evasion as a Result of Expected Utility Maximization," Journal of Transport Economics and Policy, 27(1), 69-74.

Levitt, Steven (1997), "Using Electoral Cycles in Police Hiring to Estimate the Effect of Police on Crime," American Economic Review, 87(3), 270-90.

Mussa, Michael and Shervin Rosen (1978), "Monopoly and Product Quality," Journal of Economic Theory, 18(2), 301-17.

Novos, Ian E. and Michael Waldman (1984), "The Effects of Increased Copyright Protection: An Analytical Approach,” Journal of Political Economy, 92(2), 235-46.

Oberholzer-Gee, Felix and Koleman Strumpf (2007), "The Effect of File-Sharing on Record Sales: An Empirical Analysis," Journal of Political Econonmy 115(1), 1-42.

Perlman, Yael and Yaacov Ozinci (2014), "Reducing Shoplifting by Investment in Security," Journal of the Operational Society, 65(5), 685-93.

Peukert, Christian, Jörg Claussen, and Tobias Kretschmer (2013), "Piracy and Movie Revenues: Evidence from Megaupload: A Tale of the Long Tail?", mimeo.

Polinsky, A. Mitchell and Steven Shavell (2000), "The Economic Theory of Public Enforcement of Law," Journal of Economic Literature, 38(1), 45-76.

Ramsey, Frank P. (1927), “A Contribution to the Theory of Taxation,” Economic Journal, 37(145), 47-61.

Rob, Rafael and Joel Waldfogel (2007), "Piracy on the Silver Screen," Journal of Industrial Economics, 55(3), 379-95.

Rob, Rafael and Joel Waldfogel (2006), "Piracy on the High C's: Music Downloading, Sales Displacement, and Social Welfare in a Sample of College Students," Journal of Law and Economics, 49(1), 29-62.

Timoumi, Anne and Anne T. Coughlan (2014), "Wardrobing: Is it Really All That Bad?," mimeo.

Tirole, Jean (1988), The Theory of Industrial Organization, Cambridge, MA: MIT Press.

Vernik, Dinah A. Devavrat Purohit, and Preyas S. Desai (2011), "Music Downloads and the Flop Side of Digital Rights Management," Marketing Science, 30(6), 1011-27.

Waldfogel, Joel (2012a), "Copyright Protection, Technological Change, and the Quality of New Products: Evidence from Recorded Music since Napster," Journal of Law and Economics, 55(4), 715-40. 
Waldfogel, Joel (2012b), "Digital Piracy: Empirics," in: Peitz, Martin and Joel Waldfogel (eds.), The Oxford Handbook of the Digital Economy, Oxford University Press, 531-46.

Yaniv, Gideon (2009), "Shoplifting, Monitoring, and Price Determination," Journal of Socio-Economics, 38(4), 608-10.

Zentner, Alejandro, "Measuring the Effect of File Sharing on Music Purchases,", Journal of Law and Economics, 49(1), 63-90. 